Ärztliche Erfahrung beschränkt sich nicht auf medizinisches Fachwissen.

Sie entsteht auch aus den mehr oder minder alltäglichen, heiter,

\title{
Als die Polygamie nach Deutschland kam
}

\begin{abstract}
- Ich betreue seit Herbst 2015 Flüchtlinge in einer Notunterkunft und habe dabei sehr viel Positives und Bereicherndes erlebt - die Menschen aus Syrien und dem Irak, aus Nordafrika und Nigeria sind mir und den Kollegen allesamt freundlich und dankbar begegnet. Auch
\end{abstract}

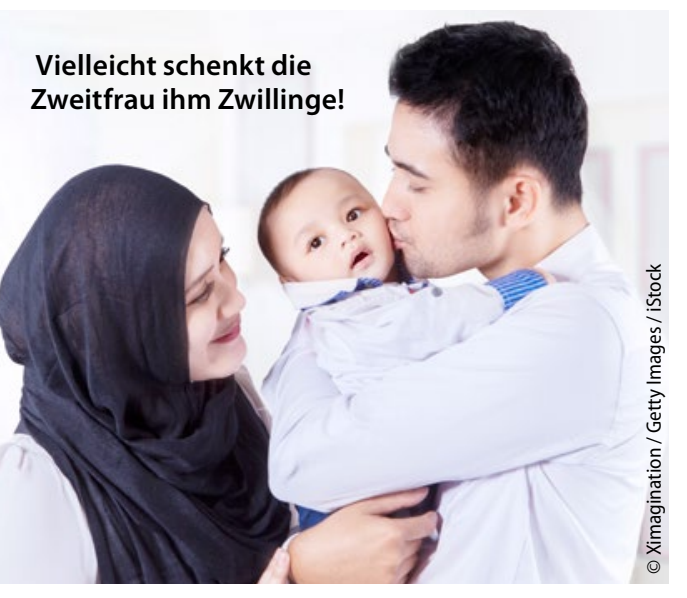

habe ich als Frau keinerlei Respektlosigkeiten von Männern erlebt.

Eine Erfahrung jedoch hat mich nachhaltig beeindruckt und auch irritiert. Zwei junge Syrerinnen kamen mit jeweils einem Säugling und einem älteren Kind zu uns in die Praxis. Die eine - ihr Baby war drei Monate alt - wünschte einen Schwangerschaftstest. Als das negative Ergebnis vorlag, traten der Ehemann und der sympathische algerische Übersetzer auf den Plan. Sie erklärten mir, dass jetzt doch der richtige Zeitpunkt sei, um der Frau durch eine Injektion mit follikelstimulierendem Hormon zu einer Zwillingsschwangerschaft zu verhelfen. Eine solche sei dringend erwünscht!

Perplex gab ich zu bedenken, dass die Frau zurzeit doch wohl andere Probleme habe, und dass die Kasse die Behandlung sowieso nicht übernehmen würde. Dann schoss mir ein weiterer Gedanke durch den Kopf und ich fragte, welche der beiden jungen Frauen eigentlich die Ehefrau war. „Beide natürlich!“, antwortete der Dolmetscher.

Auf seine offene Frage, ob ich damit ein Problem hätte, konnte ich nur antworten, dass ich als Christin die Konstellation nicht gutheißen könne, und dass auch unser Zivilrecht die Polygamie nicht vorsehe. Gleichzeitig sei es ja nicht mein Recht, über muslimische Gepflogenheiten zu urteilen.

Was soll man da sonst sagen? Ich denke, die Begegnung illustriert gut, mit welchen kulturellen und sozialen Herausforderungen wir es mitunter zu tun haben. Die spannende Frage wird sein, welchen Platz solche familiären Konstellationen künftig in unserer Gesellschaft haben werden.

Dr. Hedwig Hamers, Finnentrop-Heggen

\section{Zu Hause ist es doch am schlimmsten}

— „Frau Doktor, ich brauche mal eine Auszeit!", brach es aus dem Mann heraus. Ich verstand ihn. Vor vielen Jahren hatte er seine sardische Heimat verlassen, um in Deutschland zu rackern. Schichtdienst am Flughafen. Jetzt war er platt, und zu allem Überfluss hatte er sich auch noch eine dicke Bronchitis zugezogen. Kurz brach mir der Schweiß aus, weil ich an den Trend bei jungen
Leuten dachte, ein Jahr auf Selbstfindungstrip nach Australien zu gehen. Mein Patient war aber mit einer Woche Arbeitsunfähigkeit ganz zufrieden, mehr wollte er gar nicht.

Als er Ende der Woche zur Befundkontrolle kam, war er völlig durch den Wind. Ich bot ihm eine Verlängerung der Krankmeldung an. „Um Gottes Willen, ich will wieder an die Arbeit!", rief er. „Meine Frau liegt mit einem Herzinfarkt im Krankenhaus!" Um ihn ein bisschen runterzubringen, wechselte ich das Thema schnell auf seinen Sohn. „Mein Sohn? Der hat sich beim Fußballspielen das Bein gebrochen! Bitte lassen Sie mich nächste Woche wieder arbeiten!“, flehte er. Na, dann.

Dr. Luise Hess, Darmstadt 